Scientific journal

\section{PHYSICAL AND MATHEMATICAL EDUCATION}

Has been issued since 2013.

Науковий журнал

ФІЗИКО-МАТЕМАТИЧНА ОСВІТА

Видається з 2013.
ISSN 2413-158X (online)

ISSN 2413-1571 (print)

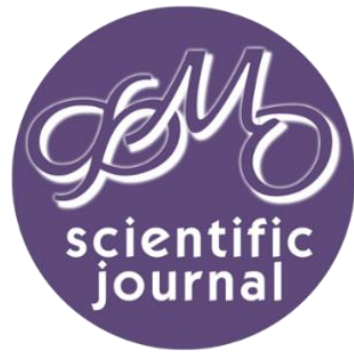

http://fmo-journal.fizmatsspu.sumy.ua/

Володко И.М., Черняева С.В., Эглите И.В. Формирование исследовательских умений на примере научноисследовательской деятельности учащихся средних школ Латвии. Фізико-математична освіта. 2019. Випуск 4(22). C. 51-55.

Volodko I., Cernajeva S., Eglite I. Formation of research abilities on the example of scientific research activity of high school students of latvia's secondary schools. Physical and Mathematical Education. 2019. Issue 4(22). P. 51-55.

DOI 10.31110/2413-1571-2019-022-4-008

удк: 373.51

И.М. Володко

Рижский технический университет, Латвия inta.volodko@rtu.Iv

ORCID: 0000-0002-7971-9688

С.В. Черняева

Рижский технический университет, Латвия sarmite.cernajeva@rtu.Iv

ORCID: 0000-0002-5106-646X

И.В. Эглите

Рижский технический университет, Латвия irina.eglite@rtu.Iv

ORCID: 0000-0002-5264-8015

\title{
ФОРМИРОВАНИЕ ИССЛЕДОВАТЕЛЬСКИХ УМЕНИЙ НА ПРИМЕРЕ НАУЧНО-ИССЛЕДОВАТЕЛЬСКОЙ ДЕЯТЕЛЬНОСТИ УЧАЩИХСЯ СРЕДНИХ ШКОЛ ЛАТВИИ
}

\begin{abstract}
АНОТАЦІЯ
Формулировка проблемы. В качестве одного из методов обучения в средней школе используется научно-исследовательская деятельность старшеклассников. Это самостоятельное исследование учащегося, которое развивает компетентность в отношении сущности, организации и методов научного исследования. Его цель - повысить интеллектуальный и творческий потенциалы школьников. Научно-исследовательская работа также может проводиться в научных областях, которые не включены в учебные планы средней школы в качестве отдельных предметов (например, педагогика, инженерные науки, социология, право, наука о здоровье).

Материалы и методы. В статье даны ссылки на публикации, связанные с научно-исследовательской деятельностью старшеклассников, а также рекомендации в области разработки и оценки работ. При проведении исследований ученик демонстрирует свою способность целенаправленно использовать и анализировать научную литературу и другие источники информации, выбирать подходящие методы исследования для достижения цели, анализировать полученные данные, делать логические, причинно-следственные суждения, делать выводы. В то же время развиваются аналитические способности ученика, навыки критического мышления, способность использовать теоретические знания при исследовании конкретных проблем, а также навыки презентации.

Результаты. Для школьника важно почувствовать остроту проблемы, которая затем определяет интерес к исследованию, а также к его завершению и описанию. Исследование проводится на базе школы, вуза, научно-исследовательского учреждения, в котором работает научный руководитель. Однако и школьник, и руководитель должны помнить, что руководитель проекта не несет ответственности за результаты работы ученика, оказывая лишь поддержку в процессе работы.
\end{abstract}

КлЮчОвІ СлОвА: научно-исследовательская работа, научно-исследовательский проект, формирование исследовательских умений, управление обучением, компетентность, средняя школа.

\section{ВВЕДЕНИЕ}

Постановка проблемы. Сегодняшний мир характеризуется глобализацией, развитием информационных технологий, поэтому деятельность людей становится все более разнообразной и непредсказуемой. Сегодняшние дети должны научиться жить в постоянно меняющемся мире и в будущем быть готовыми к созданию беспрецедентной экономической, политической, социальной и культурной среды. В Латвии с 2018/2019 учебного года начался постепенный переход к компетентностному подходу в содержании обучения в школах и в дошкольных учреждениях (с 1,5 до 18 лет): с 2018/2019 учебного года дошкольное обучение, 1-й и 4-й класс; с 2019/2020 учебного года - 2, 5 , 7 и 10 классы; с 
2020/2021 учебного года - 3-й, 6-й, 8-й и 11-й классы; и в завершении в 2021/2022 учебном году - 9 и 12 классы. Внедряя компетентностный подход, будет поддерживаться система предметов, укрепляющая сотрудничество между учителями на уровне школ в планировании и осуществлении преподавательской работы.

Анализ актуальных исследований. «Задача современной школы - подготовить детей и молодых людей к успешному будущему в меняющемся мире, не только приобрести знания и использовать их целенаправленно и ответственно, но также развить способность и желание продолжать обучение. Глобальные тенденции, исследования в области образования и опросы руководителей школ, что необходимы существенные изменения в содержании учебных программ, подходах к преподаванию и оценке знаний. Необходимо уменьшить раздробленность учебных программ, уделяя особое внимание глубокому пониманию и развитию навыков. В то же время следует уделять больше внимания развитию личности детей и молодежи, развитию привычек характера», - отметил Гунтарс Цатлакс, глава Национального центра содержания образования [Skola 2030, 2019].

Процесс получения образования как особо организованного жизненного опыта наиболее эффективно реализуется педагогами в качестве самостоятельного и творческого образовательного исследования учащихся. Поэтому в последние годы в Латвии все больше развивается научно-исследовательская деятельность учащихся [lespēju tilts, 2017]. В результате учащийся демонстрирует исследование, где необходимо оценить несколько аспектов работы и где используются знания и навыки, приобретенные по нескольким предметам.

Научно-исследовательская работа (НИР) - это эмпирическое исследование, в котором ответы на поставленные вопросы могут быть получены не только на основе имеющихся знаний и навыков, зачастую необходимы новые знания. Исследование ищет ответы на вопрос, который является актуальным для общества или науки, для которого все еще недостаточно знаний, ищутся пути решения проблемы. Тема должна быть значимой для самого школьника, для школы, или для города, или области, или для Латвии и общества в целом. НИР проводится в одной из научных областей. О проведенном исследовании свидетельствуют письменные работы, представленные на конференции. Авторы выступают с докладом в аудитории или у заранее подготовленного стенда, где суть исследования, ход и полученные результать представлены в последовательной и структурированной форме. В ходе НИР ученику рекомендуется использовать знания и навыки, приобретенные и по другим предметам, углубляя их. НИР также может проводиться в научных областях, которые не включены в учебные планы средней школы в качестве отдельных предметов (например, педагогика, инженерные науки, социология, право). При проведении исследований ученик демонстрирует свою способность целенаправленно использовать и анализировать научную литературу и другие источники информации, выбирать подходящие методы исследования для достижения цели, анализировать полученные данные, делать логические, причинно-следственные суждения, делать выводы. В то же время развиваются аналитические способности ученика, навыки критического мышления, способность использовать теоретические знания при исследовании конкретных проблем, а также навыки презентации.

Цель статьи. Обсуждаем научно-исследовательскую деятельность старшеклассников в Латвии и делимся опытом участия в математической секции (авторы являются экспертами в области математики на национальной конференции).

\section{ЦЕЛИ И ЗАДАЧИ ШКОЛЬНОЙ НАУЧНО-ИССЛЕДОВАТЕЛЬСКОЙ ДЕЯТЕЛЬНОСТИ}

Исследовательская деятельность школьников в Латвии началась еще в 2003 году, чтобы развить навыки учеников, которые требуют более глубокой обработки данных, командной работы, решений нестандартных ситуаций, взаимосвязей между теоретически изученным и реальным опытом, анализа достижений и постановки целей для будущей работы. В результате ученики разрабатывают исследовательский проект, конечным результатом которого может быть модель, цифровой прототип, стенд или отчет [VADLĪNIJAS, 2018].

В школах организована специальная проектная неделя, в течение которой четыре дня интенсивной работы над проектом, а пятый - презентация результата. Предмет исследовательской работы выбирается самим учеником, поэтому проектная работа дает школьнику возможность изучить то, что его больше всего интересует. Проект может проводиться одним учеником индивидуально или в группе до трех учеников. Однако серьезное исследование не может быть выполнено в течение четырех дней, поэтому большое количество учеников, прошедших предварительную подготовку, должны завершить проектную неделю, в основном собирая и обобщая информацию.

Научная деятельность учащихся характеризуется исследованиями в различных областях науки, ведется соответствующими учителями-предметниками или отраслевыми специалистами. Исследование проводится на базе школы, вуза, научно-исследовательского учреждения, в котором работает научный руководитель. Однако и школьник, и руководитель должны помнить, что руководитель проекта не несет ответственности за результаты работы ученика, оказывая лишь поддержку в процессе работы. Руководитель может не знать ответы на все вопросы проекта, но он должен подсказать ученику, где и как найти эти ответы.

Цели исследования учащихся:

- способствовать развитию индивидуальных компетенций и талантов учащихся в общеобразовательной сфере;

- углубить знания ученика в естественных, гуманитарных, социальных и инженерных областях;

- познакомить учащихся с темами и методами современных научных исследований с привлечением школьников к непосредственным научным разработкам;

- развить у учащихся навыки самостоятельной работы;

- развить необходимые компетенции для научной деятельности на уровне образовательного учреждения, национального и международного уровня.

Задачи исследования учащихся:

- познакомиться с сущностью, организацией и методами современного научного исследования;

- развить навыки работы со справочными материалами и источниками;

- приобрести навыки общения и сотрудничества с руководителем и специалистами отрасли; 
- развить навыки использования различных методов исследования в зависимости от отрасли;

- приобрести навыки по обработке и анализу данных, полученных в ходе исследования, а также для анализа результатов;

- развить способность публично выступать, обосновывать свое мнение.

\section{ОРГАНИЗАЦИЯ НАУЧНО-ИССЛЕДОВАТЕЛЬСКОЙ ДЕЯТЕЛЬНОСТИ ШКОЛЬНИКОВ} заведения:

Научно-исследовательская деятельность школьников организована на разных уровнях, начиная с учебного

- Школа разрабатывает свои собственные процедуры для организации и оценки НИР, принимая во внимание процедуры для организации и оценки исследовательской деятельности учащихся на этапе средней школы, а также положения и руководящие принципы для разработки и оценки государственных исследований.

- НИР школьников организованы как часть программ среднего образования в процессе обучения (уроки, индивидуальные и групповые занятия, проектная неделя).

- Разработка НИР осуществляется в соответствии с определенным планом на каждый учебный год. Каждый ученик средней школы индивидуально, вдвоем или втроем, разрабатывает и защищает, по крайней мере, одну исследовательскую работу на школьной конференции.

- Научно-исследовательская деятельность учащихся координируется заместителем директора по учебной работе или другим лицом, назначаемым директором.

- Руководителями работ являются педагоги разных предметов, у школьников могут быть консультанты специалисты соответствующей области науки, преподаватели вузов.

- Работы оценивается специально отобранным жюри, в состав которого входят не только преподаватели, но и специалисты из областей, в которых выполняются проекты.

- На школьной конференции признанные лучшими научно-исследовательские работы по усмотрению школы в соответствии с полученной оценкой номинируется на окружную конференцию.

Латвия - маленькая страна, административно разделенная на 4 региона и 110 округов. Следующий этап исследовательской деятельности учеников происходит в соответствующем округе.

- Научно-исследовательские работы учащихся общеобразовательных школ, которые получили достаточную оценку на окружной конференции, номинируются на региональную конференцию.

- Представление работ на региональную конференцию и участие в ней школьников происходит в соответствии с требованиями проведения Латвийской школьной научно-исследовательской конференции.

Лучшие школьные работы дополнительно оцениваются на региональном уровне:

- Региональная школьная научно-исследовательская конференция организуется региональным университетом в сотрудничестве с городским управлением образования.

- Организаторы обеспечивают оценку работ учащихся.

Лучшие исследовательские работы выдвигаются на национальную конференцию.

- Национальная конференция организуется Государственным образовательным информационным центром в соответствии с условиями и требованиями, указанными в положениях Латвийской конференции научных исследований школьников.

- Презентация исследовательских работ и их оценка проводится в соответствии с Руководством по разработке и оценке школьной научно-исследовательской работы.

В 2017/18 учебном году 978 учеников приняли участие в НИР конференции на национальном уровне. Работы (всего 811) были представлены в 23 разделах (рис. 1).

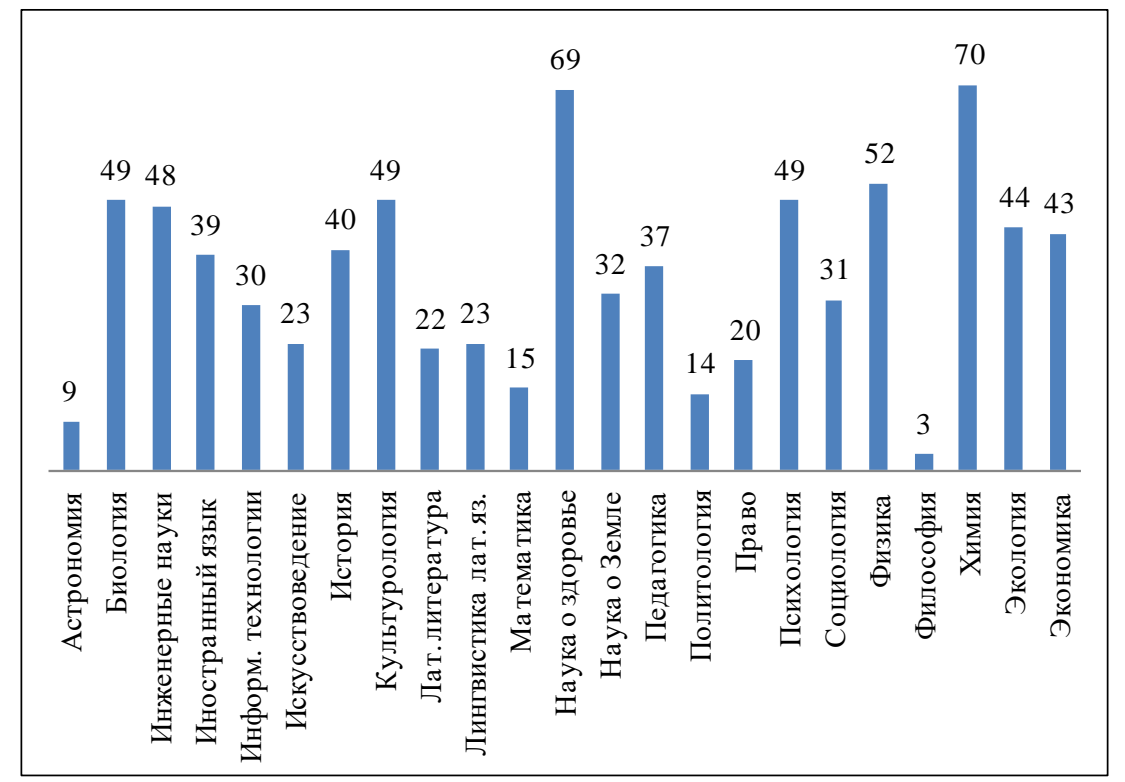

Рис. 1. Количество НИР, представленных в разных разделах в 2017/18 учебном году 
Как показывает статистика, наиболее популярными разделами с наибольшим количеством работ являлись химия и медицинские науки, а наименьшее количество работ - в разделах философии и астрономии.

В 2018/19 учебном году региональная оценка была более строгой, и на Национальную конференцию научных исследований учащихся было направлено 389 работ, в которых 117 школ представляли 462 авторов. В 2019 году работы были разделены на 6 секций: естественные науки, гуманитарные науки и искусство, инженерные науки, сельскохозяйственные, лесные и ветеринарные науки, наука о здоровье и медицинские науки, общественные науки.

Каждый раздел, в свою очередь, был разделен на подразделы. Раздел «Естественные науки» был разделен на 6 подразделов: биология, компьютерные науки и информационные технологии, физика, химия, математика, науки о Земле и окружающей среде. Всего в разделе «Естественные науки» было представлено 103 работы, распределение которых в подразделах показано на рис. 2.

В 2019 году было награждено 182 работы (45\%) и 223 ученика (48\%). Из них 39 получили первое место, 61 - второе место и 82 - третье место (рис. 3).

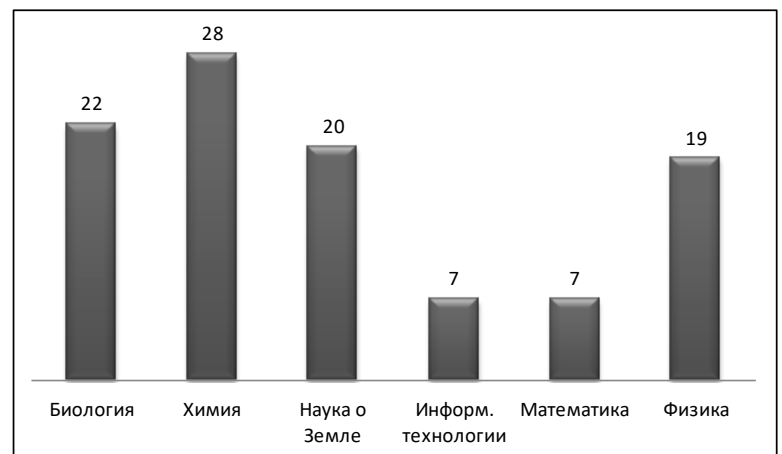

Рис. 2. Количество НИР в разделе «Естественные науки" в 2018/19 учебном году

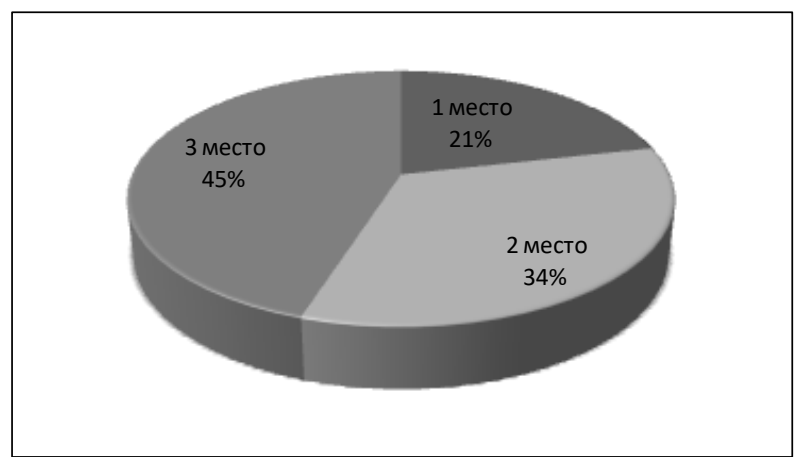

Рис. 3. Награжденные работы по призовым местам

\section{ОЦЕНКА НАУЧНО-ИССЛЕДОВАТЕЛЬСКОЙ РАБОТЫ}

В процессе исследования важно уточнить и сформулировать проблему исследования. Важно, чтобы знания, полученные в ходе исследования, имели бы практическое значение и пригодны для использования и, следовательно, актуальны. Для школьника важно почувствовать остроту проблемы, которая затем определяет интерес к исследованию, а также к его завершению и описанию. Для новизны исследования существуют два основных подхода к выбору исследовательской задачи.

Во-первых, это может быть практическая проблема, которая указывает на недостаток знаний в конкретной области. Во-вторых, проблема исследования может быть выявлена путем изучения научной литературы по конкретному вопросу. Перед началом исследования важно ознакомиться с существующей литературой. Это позволяет узнать, что уже было исследовано, а какая информация по-прежнему отсутствует. Задача исследования должна быть реалистичной и поддающейся исследованию. Описание проблемы должно быть четко сформулировано. Новизна, которая отличает исследование от всех других исследований, играет важную роль.

Оценка НИР основана на следующих критериях:

- логика научно-исследовательской работы;

- оригинальность научно-исследовательской работы;

- концепция научно-исследовательской работы;

- обзор литературы;

- описание и обоснование метода;

- анализ результатов и выводов;

- исследовательская этика;

- представление текста научно-исследовательской работы;

- презентация научно-исследовательской работы.

Учащимся рекомендуется использовать критерии оценки в качестве контрольного списка для проверки того, что работа выполнена в соответствии с требованиями научных исследований, что правильно оформлена.

Анализ результатов математической секции (авторы являются экспертами в области математики на национальной конференции) в 2017/18 учебном году 42 Латвийской школьной научно-исследовательской конференции показывает, что среди лучших работ есть не только представители школ крупных городов. Например, работа «Экстремальные полимино - цепочки единичных квадратов фиксированной длины» (научный руководитель - профессор Латвийского университета) ученицы средней школы села Эзерниеки была удостоена первого места. В общей сложности 15 школьных работ были представлены в математической секции.

К сожалению, в 2018/19 учебном году в подразделе математики было только семь работ. Из них три работь получили первое место: «Несчетность узнаваемых языковых классов, распознаваемых автоматами малой вероятности с фиксированными точками пересечения», «Анализ централизованных экзаменов по математике с 2004 года по 2018 год» и «Перестановки и магические замкнутые ломаные линии на треугольной сетке».

Успешная защита НИР на конференции в регионе или на национальной конференции может быть преимуществом при поступлении в университет. Лучшие работы и их авторы участвуют в международных школьных научных конференциях. 
В 2019 году 10 работ представляли Латвию в Международных конкурсах научно-исследовательских работ школьников. Две работы приняли участие в Международной научно-технической выставке Intel ISEF в Фениксе, США; две работы - „Genius Olympiad” в Освего, США; три работы - в Европейском конкурсе молодых ученых в Софии, Болгария; три работы - на выставке Expo-Sciences International (MILSET) в Абу-Даби, Объединенные Арабские Эмираты.

\section{выводы}

1. НИР позволяет учащимся приобретать исследовательские навыки творческим и интересным способом, учит получать, обрабатывать и анализировать данные, необходимые в исследовании, а также развивает презентационные навыки и умение аргументировать свое мнение.

2. НИР помогает подготовиться и продолжить обучение в высшем учебном заведении, осознанно выбирая подходящую карьеру в будущем.

3. Результаты исследования НИР могут быть использованы для публикации.

4. Успешная защита НИР на национальной конференции дает преимущество при поступлении в университет.

\section{Список использованных источников}

1. Skola 2030, "Izglītība mūsdienīgai lietpratībai: mācību satura un pieejas apraksts," 2019, [Online]. Available: https://www.skola2030.lv (на латышском языке)

2. lespēju tilts, "Darīt vēl labāk," 2017, [Online]. Available: http://www.iespejutilts.lv (на латышском языке)

3. VADLĪNIJAS skolēnu zinātniskās pētniecības darbu izstrādei un vērtēšanai, 2018, [Online]. Available: https://visc.gov.lv/visc/projekti/dokumenti/esf_8321/20180108_zpd_vadlinijas.pdf (на латышском языке)

\section{References}

1. Skola 2030, "Izglītība mūsdienīgai lietpratībai: mācību satura un pieejas apraksts," 2019, [Online]. Available: https://www.skola2030.lv (in Latvian)

2. lespēju tilts, "Darīt vēl labāk," 2017, [Online]. Available: http://www.iespejutilts.Iv (in Latvian)

3. VADLĪNIJAS skolēnu zinātniskās pētniecības darbu izstrādei un vērtēšanai, 2018, [Online]. Available: https://visc.gov.lv/visc/projekti/dokumenti/esf_8321/20180108_zpd_vadlinijas.pdf (in Latvian)

\section{FORMATION OF RESEARCH ABILITIES ON THE EXAMPLE OF SCIENTIFIC RESEARCH ACTIVITY OF HIGH SCHOOL STUDENTS OF LATVIA'S SECONDARY SCHOOLS \\ I. Volodko, S. Cernajeva, I. Eglite \\ Riga Technical University, Latvia}

Abstract.

Problem formulation. As one of the teaching methods in secondary school, the research activities of high school students are used. This is a student's independent research, which develops competence in relation to the nature, organization and methods of scientific research. Its goal is to increase the intellectual and creative potentials of students. Research work can also be carried out in scientific fields that are not included in the secondary school curricula as separate subjects (for example, pedagogy, engineering, sociology, law, health science).

Materials and methods. The article provides links to publications related to the research activities of high school students, as well as recommendations in the field of development and evaluation of work. When conducting research, the student demonstrates his ability to purposefully use and analyze scientific literature and other sources of information, choose the appropriate research methods to achieve the goal, analyze the data obtained, make logical, causal judgments, and draw conclusions. At the same time, the student's analytical abilities, critical thinking skills, the ability to use theoretical knowledge in the study of specific problems, as well as presentation skills are developing.

Results. It is important for the student to feel the acuteness of the problem, which then determines the interest in the study, as well as in its completion and description. The study is conducted on the basis of a school, university, research institution, in which the supervisor works. However, both the student and the leader should remember that the project manager is not responsible for the results of the student's work, providing only support in the work process.

Key words: research work, research project, the formation of research skills, teaching management, competence, high school. 